\title{
APLICAÇÃO DE ANÁLOGO DE GnRH NO MOMENTO DA INSEMINAÇÃO ARTIFICIAL COMO ALTERNATIVA PARA OTIMIZAR A TAXA DE CONCEPÇÃO EM GADO DE LEITE
}

\author{
HELEN CAROLINE GOMES PEIXOTO, \\ PAULO HENRIQUE SOUZA, \\ PAULO OTÁVIO MEDEIROS DE DEUS VIEIRA, \\ ANDRIELLE THAINAR MENDES CUNHA.
}

\begin{abstract}
RESUMO - Introdução: A inseminação artificial (IA) é uma das biotécnicas mais utilizadas dentro da pecuária bovina. Embora a IA seja realizada sem a aplicação de hormônios exógenos, o uso do análogo do hormônio liberador de gonadotrofina $(\mathrm{GnRH})$ imediatamente após a inseminação artificial tem sido proposto para otimizar os resultados das taxas de concepção com o uso da IA, uma vez que o análogo do GnRH estimula a hipófise para a liberação do hormônio folículo estimulante (FSH) e do hormônio luteinizante (LH). O objetivo deste trabalho foi avaliar o uso do análogo de GnRH em vacas leiteiras no momento da realização da IA. Para responder aos questionamentos propostos, o experimento teve início com a detecção do estro seguido de IA. No momento da IA foi realizada a aplicação do hormônio via endovenosa em 40 vacas, distribuídas em multíparas e primíparas. Para o grupo controle, 40 novilhas foram utilizadas sem tratamento hormonal. Os resultados obtidos mostraram que embora tenha sido feito o uso do análogo de GnRH, a taxa de concepção dos animais não foi alterada, sendo que o grupo controle apresentou maior taxa de concepção em comparação ao grupo tratado. De acordo com os resultados observados neste experimento, a aplicação do análogo de GnRH imediatamente após a realização da IA não apresenta eficácia no aumento das taxas de concepção em fêmeas bovinas multíparas ou primíparas.
\end{abstract}

PALAVRAS-CHAVE - Análogo de GnRH; Inseminação artificial; Estro.

\section{INTRODUÇÃO}

A identificação do estro em bovinos de produção leiteira é de grande importância para otimizar a eficiência reprodutiva dos animais ao utilizar a Inseminação Artificial (IA). Também conhecido popularmente como "cio", o estro é um fenômeno fisiológico do ciclo estral que tem duração de 18 a 19 horas [6], e é nesse período que a fêmea está apta à monta. Dessa forma, para que a IA seja bem conduzida e tenha boa eficiência, é importante a detecção do estro, para então conduzir a inseminação artificial [2].

Atualmente, a biotécnica reprodutiva mais disseminada nos rebanhos bovinos é IA [1]. O uso desta biotécnica traz ao produtor vantagens como a otimização do controle zootécnico da propriedade, reduz a disseminação de doenças sexualmente transmissíveis, diminuí os índices de acidentes entre os animais na hora da monta natural ou a territorialidade entre reprodutores. A utilização da IA também é responsável por aumentar consideravelmente o melhoramento genético, tornando elevada a produção do rebanho bovino brasileiro. Em fazendas que atuam com a pecuária leiteira, a IA interfere positivamente na eficiência reprodutiva das vacas, permite o uso de sêmen sexado, além de uniformizar o nascimento de bezerros através da estação de monta controlada [1].

De maneira convencional, a IA não utiliza a administração de hormônios exógenos como é feito com a inseminação artificial em tempo fixo (IATF). No entanto, para melhorar a eficiência da biotécnica, alguns trabalhos avaliam a aplicação do hormônio liberador de gonadotrofinas (GnRH) via endovenosa. O análogo de $\mathrm{GnRH}$ tem sido utilizado com o objetivo de otimizar os resultados de prenhez com a aplicação do hormônio via endovenosa no momento da IA. O objetivo do uso do hormônio é induzir a ovulação do folículo dominante (FD) e prolongar a sobrevida do corpo lúteo $(\mathrm{CL})$ pós-fecundação, estrutura endócrina responsável pela produção de progesterona, que é o hormônio responsável pela manutenção da gestação ( [4];[ [5]; [8]; [11]).

O objetivo deste trabalho foi testar o efeito da aplicação do análogo de GnRH no momento da IA como ferramenta para melhorar as taxas de concepção. 


\section{METODOLOGIA}

$\mathrm{O}$ experimento foi realizado na agropecuária Palma, localizada na cidade de Luziânia-GO. A agropecuária atua na criação de bovinos para a produção de leite, sendo seu rebanho composto por animais holandeses e mestiços, criados em sistema "free stall" e ordenhados três vezes ao dia. Para a realização do experimento foram selecionadas 40 fêmeas, sendo critério de seleção a identificação de características comportamentais que permitiram a identificação do estro. Após a avaliação do estro, foi realizado o exame ginecológico e avaliação ultrassonográfica do trato reprodutivo. Para a realização da IA, foram selecionadas apenas fêmeas com folículo dominante com diâmetro entre $11 \mathrm{~mm}$ a $25 \mathrm{~mm}$.

Para detecção do estro, foi realizada observação diária do comportamento das fêmeas, nos turnos matutino e vespertino, momento que as vacas foram direcionadas a piquetes (figura 1), por 20 minutos, e observadas visualmente para a identificação de sinais que condiziam com o período do estro.

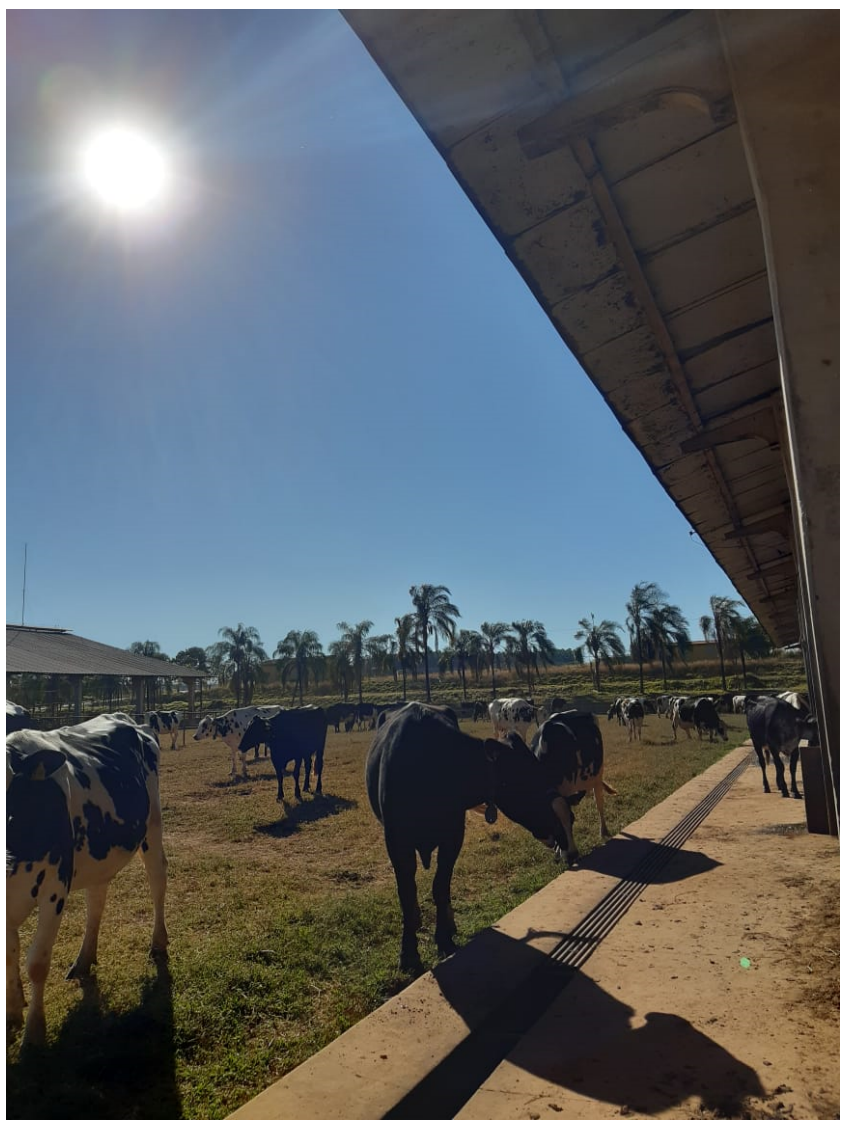

Figura 1. Vacas soltas no piquete para detecção visual do estro.

Os principais sinais observados foram: vulva hiperêmica e edemaciada, presença de muco cervical, inquietação, falta de apetite e aceitação de monta. Os animais que apresentaram as alterações condizentes com o estro foram levados para avaliação (figura 2).

Após a observação dos sinais do estro, as avaliações ginecológicas foram realizadas, destacando-se a avaliação com ultrassonográfica dos ovários para identificar a presença do
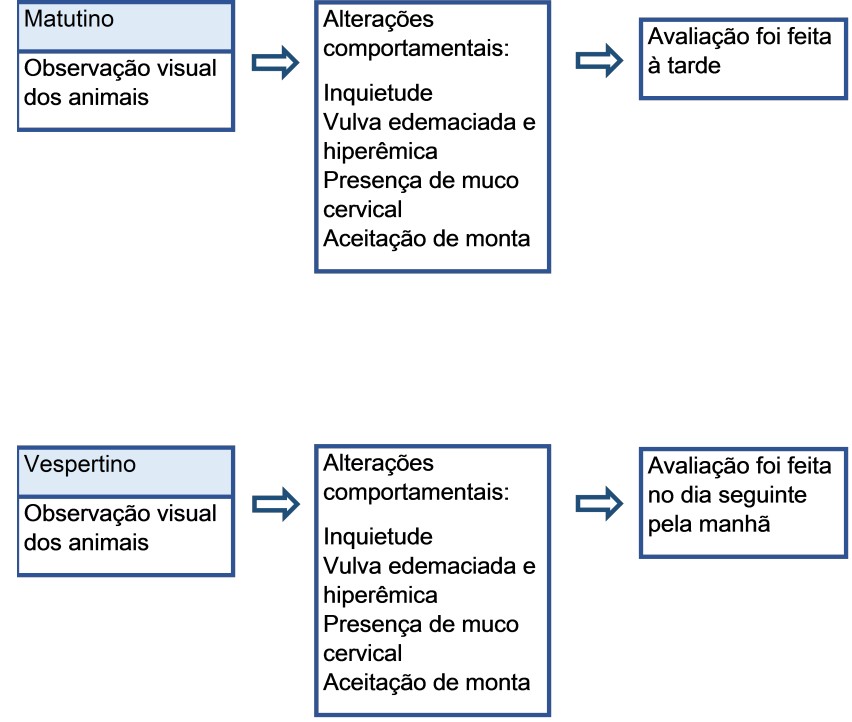

Figura 2. Fluxograma da detecção do estro, alterações comportamentais observadas e horário da avaliação do animal.

folículo dominante e sua mensuração [10]. As fêmeas que apresentaram folículo dominante dentro das dimensões préestabelecidas foram inseminadas com sêmen criopreservado de reprodutores conhecidos e testados, comercializado através de central de sêmen. Após a IA foi aplicado $0,1 \mathrm{mg}$ de análogo de GnRH via endovenosa (figura 3).

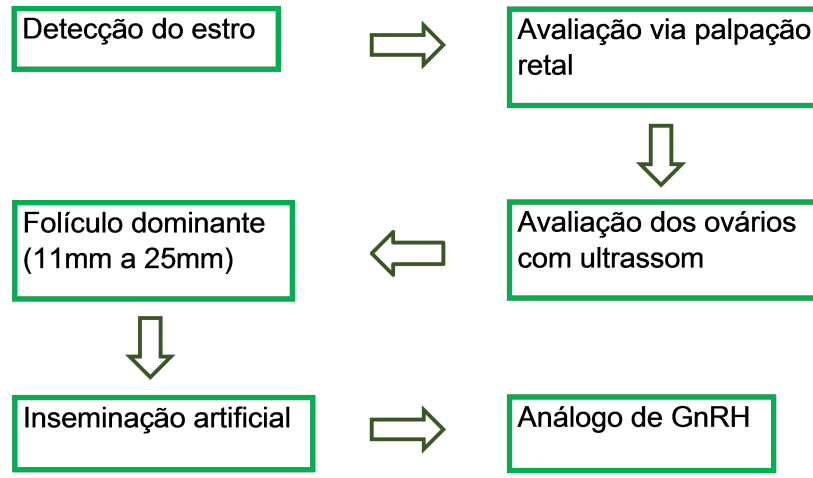

Figura 3. Fluxograma do experimento realizado.

Logo após a IA as vacas foram levadas para seus respectivos lotes e só retornaram para manejo de reprodução as fêmeas que apresentaram sinais de estro, ou após 31 dias de inseminadas, para uma avaliação ginecológica e diagnóstico de gestação. O diagnóstico de gestação foi feito com a ajuda de um ultrassom, momento que foram avaliados os cornos uterino direito e esquerdo, a presença de líquido amniótico, saco gestacional, vesícula embrionária e embrião

O grupo controle, selecionado para o experimento, foi composto por novilhas da recria e a seleção foi feita utilizando o critério de inserir apenas animais que não faziam aplicação de nenhum tipo de hormônio exógeno. As fêmeas novilhas foram criadas no sistema "free stall", assim como 
as vacas do grupo tratamento. As novilhas também passaram pela detecção visual do estro duas vezes ao dia, e os animais com características comportamentais de cio foram encaminhadas para avaliação ginecológica, mensuração folicular e em seguida a IA. Os animais só voltaram para avaliação após 31 dias de inseminados para diagnóstico de gestação.

A análise estatística dos dados obtidos neste estudo foi feita através do teste qui-quadrado, os resultados foram considerados diferentes quando $\mathrm{P}$ 0,05.

\section{RESULTADOS E DISCUSSÃO}

Conforme pode ser observado na figura 4 apenas $12,5 \%$ dos animais tratados apresentaram prenhez positiva, sendo inferior ao observado no grupo controle que apresentou $47,5 \%$ de prenhez $(\mathrm{p}=0,000347)$.

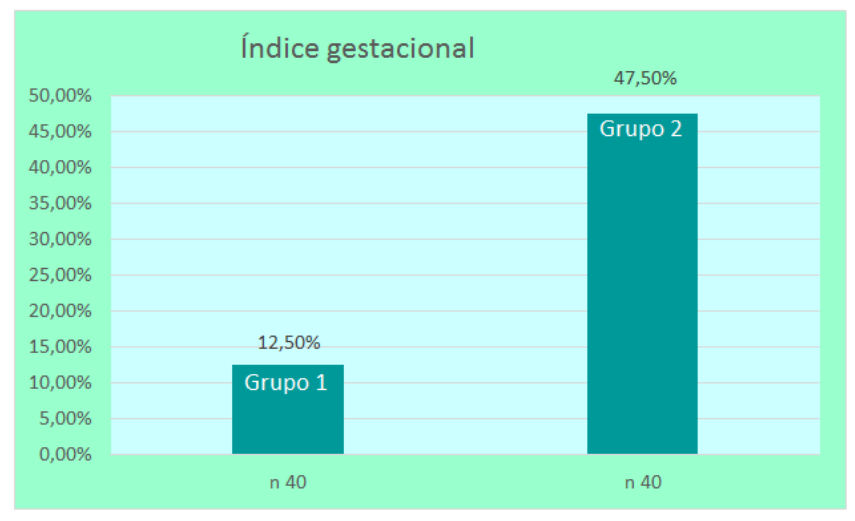

Figura 4. Grupo 1: grupo tratamento. Grupo 2: grupo controle.

A aplicação do análogo de GnRH logo após a IA foi feita com o objetivo de estimular a ovulação do folículo dominante, pois sua ação é descrita como liberador de LH, hormônio que pode atuar no aumento da taxa de ovulação, além de prolongar a vida do corpo lúteo [9]. Estudos que avaliam o uso de análogo de GnRH após a IA e IATF, apontam que a absorção do análogo pode ser rápida, trazendo o efeito imediato logo após a aplicação, fazendo com que haja uma precoce ovulação do folículo dominante ([2];[3]). No entanto, o resultado obtido neste trabalho ao utilizar o tratamento hormonal não foi o esperado.

Ao observar a não eficiência do uso do análogo de GnRH, é possível levantar a discussão da real necessidade de administração exógena deste hormônio no momento da IA, uma vez que é sabido que nesta fase do ciclo estral o GnRH endógeno já se apresenta em altas quantidades. Desta forma, a aplicação do análogo não interferiu positivamente no resultado e não provocou um aumento nos números de fêmeas prenhas. Outra hipótese é de que como não foi feito um controle de níveis hormonais e um acompanhamento diário, talvez a aplicação tenha sido tardia, e o efeito esperado não foi alcançado, ou, em outra hipótese, a aplicação tenha sido feita cedo, e o resultado previsto não foi obtido. Por fim, variáveis como uso de doses de sêmen de diferentes reprodutores, e a IA re- alizada por mais de 2 inseminadores podem ter influenciado negativamente nos dados obtidos neste trabalho.

Em relação ao grupo controle ter resultado em mais fêmeas prenhes, é observado que em caso de animais em lactação, o ciclo estral pode demonstrar uma queda na produção dos hormônios devido ao sistema de criação e a alimentação contendo alto teor de concentrados, além disso, vacas em lactação possuem alto nível de prolactina, hormônio associado com a inibição de LH [7]. Baseado nisso, as novilhas têm uma taxa de concepção maior, pois ainda não estão em lactação.

Estas observações poderiam ser amenizadas ao homogeneizar os grupos trabalhados, distribuindo vacas multíparas, primíparas e novilhas nos grupos controle e tratamento. No entanto, para realização deste experimento não foi possível realizar esta alteração no delineamento do projeto, uma vez que o manejo reprodutivo da propriedade sempre separa os lotes de novilhas dos lotes de vacas multíparas e primíparas, e a administração do análogo de GnRH teve o intuito de otimizar justamente os resultados obtidos com as vacas multíparas e primíparas.

\section{CONCLUSÃO}

O uso do análogo de GnRH no momento da IA não foi eficiente para otimizar os índices de taxa de concepção em vacas holandesas.

\section{Referências}

[1] Baruselli P.S., Catussi B.L.C., Abreu L.A., Elliff, F.M., Silva L.G., Batista E.S., Crepaldi G.A. 2019. Evolução e perspectivas da inseminação artificial em bovinos. Rev. Bras. Reprod. Anim. 43(2): 308-314.

[2] Campos C.C., Santos R.M. 2013. Fatores que afetam as taxas de concepção e detecção do estro de retorno após a IATF em vacas holandesas. Semina: Ciências Agrárias. 36 (3).

[3] Duarte Júnior M.F., Hatamoto-Zervoudakis L.K., Zervoudakis J.T., Kocheck J.F.W., Fioravanti Filho R.S., Freitas, L.C. 2014. Aspectos relacionados à fisiologia do anestro pós-parto em bovinos. Colloquium Agrariae. 9 (2): 43-71.

[4] Fachin H. 2018. Uso de GnRH no momento da inseminação artificial como ferramenta para otimizar os resultados de protocolos de IATF em gado de corte. Tese. Universidade Federal de Santa Catarina: 1-25.

[5] González F.H.D. 2002. Introdução a endocrinologia reprodutiva veterinária. Universidade Federal Rio Grande Sul: 1-147.

[6] Hafez, E.S.E.; Hafez, B. 2004. Reprodução Animal, 7ed. São Paulo: Manole, 513.

[7] Lopes R.A. 2012. Papel da prolactina na regulação da expressão de kisspeptina e secreção do hormônio luteinizante em fêmeas. Dissertação. Universidade Federal de Minas Gerais: 1-69.

[8] Madureira G. 2020. Protocolos de IA cronometrada à base de progesterona para bovinos Bos indicus II: Resultados reprodutivos do protocolo do tipo EB ou GnRH, usando ou não GnRH na IA. Theriogenology. 145: 86-93.

[9] Mühl J.J., Giacomelli M., Campagnolo S.J., Borges L.F.K. Efeito da utilização de GnRH no momento da IATF em vacas holandesas em lactação.

[10] Pansani M.A., Beltran M.P. 2009. Anatomia e fisiologia do aparelho reprodutor de fêmeas bovinas. Revista Científica Eletrônica de Medicina Veterinária. 12: 2020- 2009.

[11] Prata A.B. 2018. Eficiência reprodutiva das vacas nelore submetidas a protocolos de IATF com 7, 8 ou 9 dias de dispositivo intravaginal de P4 e com ou sem GnRH no momento da IA. Sociedade Brasileira de tecnologia de embriões. 


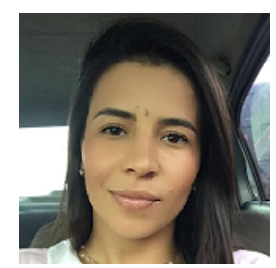

HELEN CAROLINE GOMES PEIXOTO

Médica veterinária graduada pelo Centro Universitário de Desenvolvimento do Centro Oeste UNIDESC (2020). Atua como profissional autônoma na área de reprodução animal..

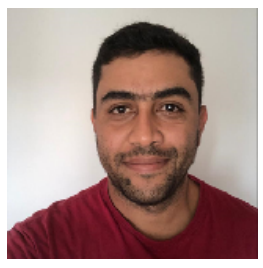

PAULO HENRIQUE SOUZA

Formação em medicina veterinária pela faculdade anhanguera de Anápolis, pós graduado em bovinocultura de leiteira. Atua como gerente e médico veterinário na agropecuária GL, Luziânia-GO.

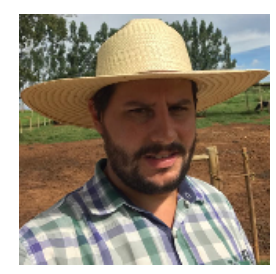

PAULO OTÁVIO MEDEIROS DE DEUS VIEIRA

Médico veterinário pela Universidade Federal de Uberlândia, pós graduando em Pecuária Leiteira pela Rehagro. Atua como veterinário responsável pela Fazenda Vera Cruz, Cristalina-GO.

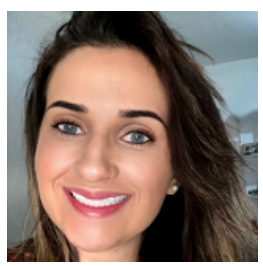

ANDRIELLE THAINAR MENDES CUNHA

Médica veterinária graduada pelas FACIPLAC (2011), mestre em Ciências Animais pela Universidade de Brasília (2015) e doutora em Biologia Animal pela Universidade de Brasília (2019). Atua na área de reprodução animal e biotecnologias da reprodução. Docente no Centro Universitário de Desenvolvimento do Centro Oeste - UNIDESC. 